\title{
Suicide Rates by Industry and Occupation - National Violent Death Reporting System, 32 States, 2016
}

\author{
Cora Peterson, $\mathrm{PhD}^{1}$; Aaron Sussell, $\mathrm{PhD}^{2}$; Jia Li, MS 3 ; Pamela K. Schumacher ${ }^{3}$; Kristin Yeoman, $\mathrm{MD}^{2}$; Deborah M. Stone, ScD ${ }^{1}$
}

In 2017, nearly 38,000 persons of working age (16-64 years) in the United States died by suicide, which represents a $40 \%$ rate increase (12.9 per 100,000 population in 2000 to 18.0 in 2017) in less than 2 decades. ${ }^{*}$ To inform suicide prevention, CDC analyzed suicide data by industry and occupation among working-age decedents presumed to be employed at the time of death from the 32 states participating in the 2016 National Violent Death Reporting System (NVDRS). $†, \S$ Compared with rates in the total study population, suicide rates were significantly higher in five major industry groups: 1) Mining, Quarrying, and Oil and Gas Extraction (males); 2) Construction (males); 3) Other Services (e.g., automotive repair) (males); 4) Agriculture, Forestry, Fishing, and Hunting (males); and 5) Transportation and Warehousing (males and females). Rates were also significantly higher in six major occupational groups: 1) Construction and Extraction (males and females); 2) Installation, Maintenance, and Repair (males); 3) Arts, Design, Entertainment, Sports, and Media (males); 4) Transportation and Material Moving (males and females); 5) Protective Service (females); and 6) Healthcare Support (females). Rates for detailed occupational groups (e.g., Electricians or Carpenters within the Construction and Extraction major group) are presented and provide insight into the differences in suicide rates within major occupational groups. CDC's Preventing Suicide: A Technical Package of

\footnotetext{
*https://www.cdc.gov/injury/wisqars.

${ }^{\dagger}$ https://www.cdc.gov/violenceprevention/nvdrs.

${ }^{S}$ In 2016, 32 states participated in NVDRS: Alaska, Arizona, Colorado, Connecticut, Georgia, Hawaii, Illinois, Indiana, Iowa, Kansas, Kentucky, Maine, Maryland, Massachusetts, Michigan, Minnesota, New Hampshire, New Jersey, New Mexico, New York, North Carolina, Ohio, Oklahoma, Oregon, Pennsylvania, Rhode Island, South Carolina, Utah, Vermont, Virginia, Washington, and Wisconsin. That year, Illinois, Pennsylvania, and Washington each collected data on $\geq 80 \%$ of violent deaths in the state, in accordance with requirements under which the state was funded for NVDRS; therefore, presented data likely underestimate suicide deaths and rates.
}

Policy, Programs, and Practices (1) contains strategies to prevent suicide and is a resource for communities, including workplace settings.

NVDRS combines data on violent deaths, including suicide, from death certificates, coroner/medical examiner reports, and law enforcement reports. Industry and occupation coding experts used CDC's National Institute for Occupational Safety

\section{INSIDE}

63 Trends in HIV-2 Diagnoses and Use of the HIV-1/HIV-2 Differentiation Test — United States, 2010-2017

67 Population-Based Surveillance for Birth Defects Potentially Related to Zika Virus Infection - 22 States and Territories, January 2016-June 2017

72 Variation in Tdap and Influenza Vaccination Coverage Among Pregnant Women by Insurance Type Florida, 2016-2018

77 Use of Tetanus Toxoid, Reduced Diphtheria Toxoid, and Acellular Pertussis Vaccines: Updated Recommendations of the Advisory Committee on Immunization Practices — United States, 2019

84 Characteristics of Persons Who Report Using Only Nicotine-Containing Products Among Interviewed Patients with E-cigarette, or Vaping, Product Use-Associated Lung Injury Illinois, August-December 2019

90 Update: Characteristics of a Nationwide Outbreak of E-cigarette, or Vaping, Product Use-Associated Lung Injury — United States, August 2019-January 2020

95 QuickStats

Continuing Education examination available at https://www.cdc.gov/mmwr/mmwr_continuingEducation.html

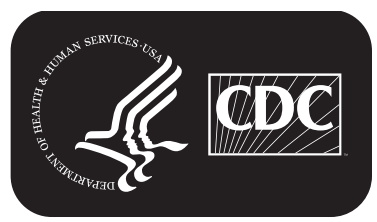

U.S. Department of Health and Human Services Centers for Disease Control and Prevention 
and Health Industry and Occupation Computerized Coding System (NIOCCS 3.0) to assign 2010 U.S. Census civilian industry and occupation codes for 20,975 suicide decedents aged 16-64 years from the 32 states participating in the 2016 NVDRS, using decedents' usual industry and occupation as reported on death certificates. Industry (the business activity of a person's employer or, if self-employed, their own business) and occupation (a person's job or the type of work they do) are distinct ways to categorize employment (2).

Suicide rates were analyzed for industry and occupational groups by sex. Population counts by occupation for rate denominators were states' civilian, noninstitutionalized current job population counts (for persons aged 16-64 years) from the 2016 American Community Survey Public Use Microdata Sample.** Replicate weight standard errors for those counts were used to calculate $95 \%$ confidence intervals (CIs) for suicide rates (3). Rates were calculated by U.S. Census code for major industry groups, major occupational groups, and detailed occupational groups with $\geq 20$ decedents; detailed occupational groups are typically more homogenous in terms of employee income, work environment, and peer group. Rates were not calculated for detailed industry groups because many decedents' industry was classifiable only by major group. The following decedents were excluded from rate calculations: military workers (327); unpaid workers $(2,863)$; those whose

I https://wwwn.cdc.gov/nioccs3.

** https://www.census.gov/programs-surveys/acs/data/pums.html. other NVDRS data sources (e.g., law enforcement reports) indicated no employment at time of death (i.e., unemployed, disabled, incarcerated, homemaker, or student) $(4)(1,783)$; and those not residing in the analysis states (223). A total of 15,779 decedents, including 12,505 (79\%) males and 3,274 (21\%) females, were included in the analysis. The analysis was conducted using Stata (version 15, StataCorp) and SAS (version 9.4, SAS Institute) statistical software.

Industry and occupational groups with suicide rates significantly $(\alpha=0.05$ ) higher than the study population (i.e., all industries or occupations: 27.4 males [95\% CI $=26.9-27.9]$ and 7.7 females $[95 \% \mathrm{CI}=7.5-8.0]$ per 100,000 population) were identified when the group's $95 \%$ CI exceeded the study population rate point estimate. Treating the population rate as a constant is reasonable when variance is small and is required for one-sample inference that recognizes the nonindependence of individual industry and occupation groups relative to the study population.

The five major industry groups with suicide rates higher than the study population by sex included 1) Mining, Quarrying, and Oil and Gas Extraction (males: 54.2 per 100,000 civilian noninstitutionalized working population, $95 \% \mathrm{CI}=44.0-64.3$ ); 2) Construction (males: $45.3,95 \% \mathrm{CI}=43.4-47.2$ ); 3) Other Services (e.g., automotive repair; males: $39.1,95 \% \mathrm{CI}=36.1-$ 42.0); 4) Agriculture, Forestry, Fishing, and Hunting (males: $36.1,95 \% \mathrm{CI}=31.7-40.5)$; and 5) Transportation and Warehousing (males: 29.8, 95\% CI = 27.8-31.9; females: 10.1, 95\% CI = 7.9-12.8) (Table 1) (Supplementary Table 1, https:// stacks.cdc.gov/view/cdc/84274). The six major occupational

The MMWR series of publications is published by the Center for Surveillance, Epidemiology, and Laboratory Services, Centers for Disease Control and Prevention (CDC), U.S. Department of Health and Human Services, Atlanta, GA 30329-4027.

Suggested citation: [Author names; first three, then et al., if more than six.] [Report title]. MMWR Morb Mortal Wkly Rep 2020;69:[inclusive page numbers].

\section{Centers for Disease Control and Prevention \\ Robert R. Redfield, MD, Director}

Anne Schuchat, MD, Principal Deputy Director

Chesley L. Richards, MD, MPH, Deputy Director for Public Health Science and Surveillance

Rebecca Bunnell, PhD, MEd, Director, Office of Science

Arlene Greenspan, PhD, Acting Director, Office of Science Quality, Office of Science

Michael F. Iademarco, MD, MPH, Director, Center for Surveillance, Epidemiology, and Laboratory Services

\section{MMWR Editorial and Production Staff (Weekly)}

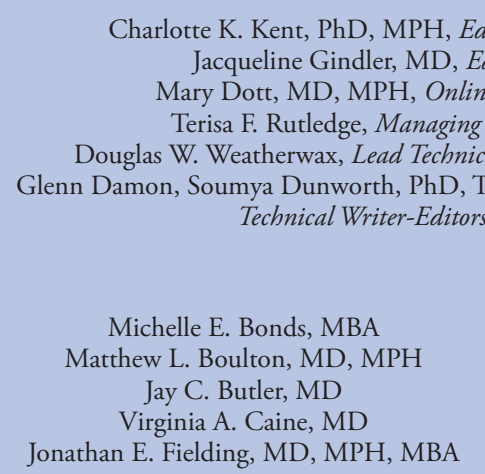

Charlotte K. Kent, PhD, MPH, Editor in Chief

Jacqueline Gindler, MD, Editor

Mary Dott, MD, MPH, Online Editor

Terisa F. Rutledge, Managing Editor

Douglas W. Weatherwax, Lead Technical Writer-Editor Technical Writer-Editors

Jonathan
MMWR Editorial Board Timothy F. Jones, MD, Chairman David W. Fleming, MD William E. Halperin, MD, DrPH, MPH Jewel Mullen, MD, MPH, MPA Jeff Niederdeppe, $\mathrm{PhD}$ Patricia Quinlisk, MD, MPH
Martha F. Boyd, Lead Visual Information Specialist Maureen A. Leahy, Julia C. Martinroe, Stephen R. Spriggs, Tong Yang, Visual Information Specialists Quang M. Doan, MBA, Phyllis H. King, Terraye M. Starr, Moua Yang, Information Technology Specialists

Stephen C. Redd, MD

Patrick L. Remington, MD, MPH

Carlos Roig, MS, MA

William Schaffner, MD

Morgan Bobb Swanson, BS 
TABLE 1. Suicide rates* for persons working in major industry and occupational groups meeting reporting criteria, by sex — National Violent Death Reporting System, 32 states, ${ }^{\dagger} 2016^{\S}$

Sex

rate $(95 \% \mathrm{Cl})$

\begin{tabular}{|c|c|c|c|}
\hline \multirow[b]{2}{*}{ Census code } & \multirow[b]{2}{*}{ Major group } & \\
\hline & & Male & Female \\
\hline Total & All industries or occupations & $27.4(26.9-27.9)$ & $7.7(7.5-8.0)$ \\
\hline \multicolumn{4}{|l|}{ Industry } \\
\hline 0170-0290 & Agriculture, Forestry, Fishing, and Hunting & $36.1(31.7-40.5)^{* *}$ & $\mathrm{NC}^{\dagger+}$ \\
\hline 0370-0490 & Mining, Quarrying, And Oil and Gas Extraction & $54.2(44.0-64.3)^{* *}$ & $\mathrm{NC}$ \\
\hline 0770 & Construction & $45.3(43.4-47.2)^{* *}$ & $9.4(6.5-13.2)$ \\
\hline 1070-3990 & Manufacturing & $23.6(22.5-24.8)$ & $7.3(6.3-8.2)$ \\
\hline $4070-4590$ & Wholesale Trade & $11.8(10.1-13.5)$ & $\mathrm{NC}$ \\
\hline $4670-5790$ & Retail Trade & $21.3(20.0-22.6)$ & $6.8(6.1-7.5)$ \\
\hline $6070-6390$ & Transportation and Warehousing & $29.8(27.8-31.9)^{* *}$ & $10.1(7.9-12.8)^{* *}$ \\
\hline 0570-0690 & Utilities & $26.3(21.9-30.7)$ & $\mathrm{NC}$ \\
\hline $6470-6780$ & Information & $19.6(16.9-22.3)$ & $6.7(4.7-9.1)$ \\
\hline $6870-6990$ & Finance and Insurance & $15.1(13.3-16.8)$ & $6.0(5.0-6.9)$ \\
\hline $7070-7190$ & Real Estate and Rental and Leasing & $16.6(13.8-19.4)$ & $7.1(5.0-9.7)$ \\
\hline $7270-7490$ & Professional, Scientific, and Technical Services & $17.6(16.2-19.0)$ & $6.4(5.4-7.3)$ \\
\hline 7570 & Management of Companies and Enterprises & $\mathrm{NC}$ & $\mathrm{NC}$ \\
\hline $7580-7790$ & Administrative and Support and Waste Management Services & $25.9(23.7-28.1)$ & $5.2(3.9-6.7)$ \\
\hline $7860-7890$ & Educational Services & $9.3(8.1-10.4)$ & $3.9(3.4-4.4)$ \\
\hline $7970-8470$ & Health Care and Social assistance & $18.7(17.0-20.4)$ & $7.5(7.0-8.0)$ \\
\hline $8560-8590$ & Arts, Entertainment, and Recreation & $27.4(24.0-30.8)$ & $9.7(7.4-12.4)$ \\
\hline $8660-8690$ & Accommodation and Food Services & $22.9(21.2-24.6)$ & $7.8(6.9-8.7)$ \\
\hline $8770-9290$ & Other Services & $39.1(36.1-42.0)^{* *}$ & $8.8(7.5-10.0)$ \\
\hline $9370-9590$ & Public Administration & $23.1(21.1-25.1)$ & $7.5(6.2-8.8)$ \\
\hline \multicolumn{4}{|l|}{ Occupation } \\
\hline 0010-0430 & Management & $17.5(16.4-18.6)$ & $5.7(5.0-6.5)$ \\
\hline 0500-0950 & Business and Financial Operations & $11.5(10.0-13.0)$ & $4.7(3.8-5.5)$ \\
\hline $1000-1240$ & Computer and Mathematical & $16.2(14.5-17.9)$ & $6.4(4.5-8.9)$ \\
\hline $1300-1560$ & Architecture and Engineering & $23.2(20.6-25.7)$ & $8.2(4.7-13.4)$ \\
\hline $1600-1965$ & Life, Physical, and Social science & $21.4(16.3-27.6)$ & $5.3(3.0-8.6)$ \\
\hline 2000-2060 & Community and Social Service & $15.4(11.7-20.0)$ & $6.2(4.7-8.2)$ \\
\hline $2100-2160$ & Legal & $16.3(12.1-21.7)$ & $7.9(5.4-11.2)$ \\
\hline $2200-2550$ & Education, Training, and Library & $9.9(8.3-11.6)$ & $3.9(3.3-4.6)$ \\
\hline $2600-2960$ & Arts, Design, Entertainment, Sports, and Media & $32.0(28.2-35.8)^{* *}$ & $8.8(6.7-11.5)$ \\
\hline $3000-3540$ & Healthcare Practitioners and Technical & $23.6(20.8-26.3)$ & $8.5(7.6-9.4)$ \\
\hline $3600-3655$ & Healthcare Support & $23.6(17.0-32.1)$ & $10.6(9.2-12.1)^{* *}$ \\
\hline $3700-3955$ & Protective Service & $26.4(23.7-29.1)$ & $14.0(9.9-19.2)^{* *}$ \\
\hline $4000-4160$ & Food Preparation and Serving Related & $21.1(19.2-22.9)$ & $7.8(6.7-8.8)$ \\
\hline $4200-4250$ & Building and Grounds Cleaning and Maintenance & $26.7(24.4-29.0)$ & $6.9(5.3-8.7)$ \\
\hline $4300-4650$ & Personal Care and Service & $25.0(21.2-28.8)$ & $8.4(7.2-9.5)$ \\
\hline 4700-4965 & Sales and Related & $20.7(19.3-22.1)$ & $7.1(6.3-7.8)$ \\
\hline $5000-5940$ & Office and Administrative Support & $14.2(12.9-15.5)$ & $5.4(4.9-5.9)$ \\
\hline $6000-6130$ & Farming, Fishing, and Forestry & $31.4(25.6-37.1)$ & $\mathrm{NC}$ \\
\hline $6200-6940$ & Construction and Extraction & $49.4(47.2-51.6)^{* *}$ & $25.5(15.7-39.4)^{* *}$ \\
\hline $7000-7630$ & Installation, Maintenance, and Repair & $36.9(34.6-39.3)^{* *}$ & $\mathrm{NC}$ \\
\hline $7700-8965$ & Production & $27.5(25.9-29.2)$ & $6.8(5.6-8.1)$ \\
\hline $9000-9750$ & Transportation and Material Moving & $30.4(28.8-32.0)^{* *}$ & $12.5(10.2-14.7)^{* *}$ \\
\hline
\end{tabular}

Abbreviations: $\mathrm{Cl}=$ confidence interval; $\mathrm{NC}=$ not calculated.

* Per 100,000 civilian, noninstitutionalized working persons aged 16-64 years.

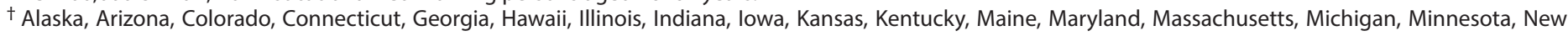

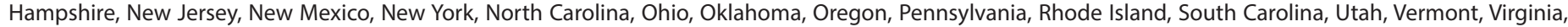
Washington, and Wisconsin.

$\S$ Number of suicide decedents $=15,779$.

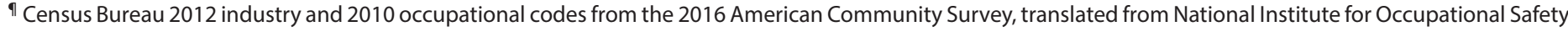

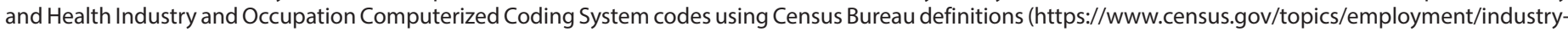
occupation/guidance/code-lists.html).

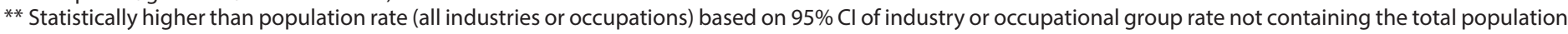
rate point estimate.

${ }^{\dagger+} \mathrm{NC}$ indicates that rate was not calculated because the number of decedents was $<20$. 
groups with higher rates included 1) Construction and Extraction (males: 49.4, 95\% CI $=$ 47.2-51.6; females: 25.5, 95\% CI $=15.7-39.4)$; 2) Installation, Maintenance, and Repair (males: 36.9, 95\% CI $=34.6-39.3$ ); 3) Arts, Design, Entertainment, Sports, and Media (males: 32.0, 95\% CI $=28.2-35.8)$; 4) Transportation and Material Moving (males: $30.4,95 \% \mathrm{CI}=28.8-32.0$; females: 12.5 , $95 \% \mathrm{CI}=10.2-14.7)$; 5) Protective Service (females: 14.0, 95\% CI $=9.9-19.2$ ); and 6) Healthcare Support (females: $10.6,95 \% \mathrm{CI}=9.2-12.1)$.

Rates could be calculated for 118 detailed occupational groups for males and 32 for females (Supplementary Table 2, https://stacks.cdc.gov/view/cdc/84275). Some occupational groups with suicide rates significantly higher than those of the study population were only identifiable through observation at the detailed group level (Table 2). Among males, these detailed groups included the following seven groups: 1) Fishing and hunting workers (part of the Farming, Fishing, and Forestry major occupational group); 2) Machinists (Production major group); 3) Welding, soldering, and brazing workers (Production major group); 4) Chefs and head cooks (Food Preparation and Serving Related major group); 5) Construction managers (Management major group); 6) Farmers, ranchers, and other agricultural managers (Management major group); and 7) Retail salespersons (Sales and Related major group). Among females, these detailed groups included the following five groups: 1) Artists and related workers (Arts, Design, Entertainment, Sports, and Media major group); 2) Personal care aides (Personal Care and Service major group); 3) Retail salespersons (Sales and Related major group); 4) Waiters and waitresses (Food Preparation and Serving Related major group); and 5) Registered nurses (Healthcare Practitioners and Technical major group). Groups with highest rate point estimates (e.g., female Artists and related workers and male Fishing and hunting workers) also had wide 95\% CIs (Table 2), based on relatively low numbers of decedents and relatively small working populations (Supplementary Table 2, https:// stacks.cdc.gov/view/cdc/84275).

\section{Discussion}

This report used data from 32 states to provide updated population-level suicide rates for major occupational groups and new information on suicide rates for major industry groups and detailed occupational groups. Estimates for most major occupational groups are similar, although not directly comparable, to previous estimates that were based on 2015 NVDRS data from 17 states (4). Recent NVDRS expansion to 50 states might facilitate direct comparisons over time by industry and occupation nationwide. These findings highlight opportunities for targeted prevention strategies and further investigation of work-related factors that might increase risk of suicide. Previous research indicates suicide risk is associated with low-skilled work (5), lower education ( 6 ), lower absolute and relative socioeconomic status (7), work-related access to lethal means (8), and job stress, including poor supervisory and colleague support, low job control, and job insecurity (9). Industry, labor, and professional associations, as well as employers, and state and local health departments can use this information to focus attention and resources on suicide prevention. Future research might examine these and other risk factors among the industries and occupations identified in this report as having high suicide rates.

This report estimated suicide rates comprehensively for industry and occupational groups meeting sample size criteria and identified groups with rates higher than the study's population rate. Although relative comparisons of suicide rates in this manner are useful for prevention purposes, these results should not overshadow the essential fact that the suicide rate in the U.S. working-age population overall has increased by $40 \%$ in less than 2 decades. Therefore, all industry sectors and occupational groups can contribute to reducing suicide incidence.

The findings in this report are subject to at least five limitations. First, this study did not address confounding factors that might account for different suicide rates among and within industry or occupational groups. Second, it did not address suicide among unemployed decedents, military or unpaid workers, or those aged $>64$ years (9). Third, the numerator and denominator data were not a direct match for calculating rates; death certificates reflect decedents' usual industry and occupation, and available population size data refer to the number of persons by current job. Fourth, the results are based on data from 32 states and are therefore not nationally representative. Finally, three states contributing to the 2016 NVDRS did not collect data on all violent deaths. Other limitations of NVDRS analysis using death certificate industry and occupation data have been described previously (4).

All industries and occupations can benefit from a comprehensive approach to suicide prevention. CDC's Preventing Suicide: A Technical Package of Policy, Programs, and Practices (1) provides strategies with the best available evidence to prevent suicide and can serve as a resource for communities and employers. Workplace-specific strategies include 1) promoting help-seeking; 2) integrating workplace safety and health and wellness programs to advance the overall well-being of workers; 3) referring workers to financial and other helping services; 4) facilitating time off and benefits to cover supportive services; 5) training personnel to detect and appropriately respond to suicide risk; 6) creating opportunities for employee social connectedness; 7) reducing access to lethal means among persons at risk; and 8) creating a crisis response plan sensitive to the 
TABLE 2. Detailed occupational groups meeting reporting criteria with male and female suicide rates* higher $^{\dagger}$ than the population rate (all occupations) and associated major occupational groups and rates — National Violent Death Reporting System, 32 states, $\$ 2016^{\natural}$

\begin{tabular}{|c|c|c|c|c|c|}
\hline $\begin{array}{l}\text { Sex/Census } \\
\text { code }^{* *}\end{array}$ & Detailed occupational group & Rate $(95 \% \mathrm{Cl})^{\dagger}$ & Census code ${ }^{* *}$ & Part of major occupational group & Rate $(95 \% \mathrm{Cl})$ \\
\hline \multicolumn{6}{|l|}{ Male } \\
\hline 6100 & Fishing and hunting workers & $119.9(60.9-215.6)^{\dagger}$ & $6000-6130$ & Farming, Fishing, and Forestry & $31.4(25.6-37.1)$ \\
\hline 2750 & Musicians, singers, and related workers & $96.5(63.7-141.1)^{\dagger}$ & $2600-2960$ & Arts, Design, Entertainment, Sports, and Media & $32.0(28.2-35.8)^{\dagger}$ \\
\hline 2600 & Artists and related workers & $93.5(60.7-138.5)^{\dagger}$ & $2600-2960$ & Arts, Design, Entertainment, Sports, and Media & $32.0(28.2-35.8)^{\dagger}$ \\
\hline 6530 & Structural iron and steel workers & $79.0(43.5-134.0)^{\dagger}$ & $6200-6940$ & Construction and Extraction & $49.4(47.2-51.6)^{\dagger}$ \\
\hline 7360 & Millwrights & $78.7(39.8-142.4)^{\dagger}$ & $7000-7630$ & Installation, Maintenance, and Repair & $36.9(34.6-39.3)^{\dagger}$ \\
\hline 6220 & $\begin{array}{l}\text { Brickmasons, blockmasons, stonemasons, } \\
\text { and reinforcing iron and rebar workers }\end{array}$ & $67.6(45.7-97.0)^{\dagger}$ & $6200-6940$ & Construction and Extraction & $49.4(47.2-51.6)^{\dagger}$ \\
\hline 6515 & Roofers & $65.2(46.1-90.0)^{\dagger}$ & $6200-6940$ & Construction and Extraction & $49.4(47.2-51.6)^{\dagger}$ \\
\hline 7200 & $\begin{array}{l}\text { Automotive service technicians and } \\
\text { mechanics }\end{array}$ & $64.8(57.4,72.3)^{\dagger}$ & $7000-7630$ & Installation, Maintenance, and Repair & $36.9(34.6-39.3)^{\dagger}$ \\
\hline 8030 & Machinists & $64.2(53.1-75.3)^{\dagger}$ & $7700-8965$ & Production & $27.5(25.9-29.2)$ \\
\hline 6260 & Construction laborers & $62.0(56.7-67.3)^{\dagger}$ & $6200-6940$ & Construction and Extraction & $49.4(47.2-51.6)^{\dagger}$ \\
\hline 7010 & $\begin{array}{l}\text { Computer, automated teller, and office } \\
\text { machine repairers }\end{array}$ & $60.8(41.8-86.1)^{\dagger}$ & $7000-7630$ & Installation, Maintenance, and Repair & $36.9(34.6-39.3)^{\dagger}$ \\
\hline 6240 & Carpet, floor, and tile installers and finishers & $55.2(35.3-83.1)^{\dagger}$ & $6200-6940$ & Construction and Extraction & $49.4(47.2-51.6)^{\dagger}$ \\
\hline 7150 & Automotive body and related repairers & $54.9(34.4-83.9)^{\dagger}$ & $7000-7630$ & Installation, Maintenance, and Repair & $36.9(34.6-39.3)^{\dagger}$ \\
\hline 6230 & Carpenters & $54.7(49.0-60.4)^{\dagger}$ & $6200-6940$ & Construction and Extraction & $49.4(47.2-51.6)^{\dagger}$ \\
\hline 8140 & Welding, soldering, and brazing workers & $53.6(45.2-62.1)^{\dagger}$ & $7700-8965$ & Production & $27.5(25.9-29.2)$ \\
\hline 6320 & $\begin{array}{l}\text { Construction equipment operators except } \\
\text { paving, surfacing, and tamping equipment } \\
\text { operators }\end{array}$ & $52.8(42.2-63.4)^{\dagger}$ & $6200-6940$ & Construction and Extraction & $49.4(47.2-51.6)^{\dagger}$ \\
\hline 9620 & $\begin{array}{l}\text { Laborers and freight, stock, and material } \\
\text { movers, hand }\end{array}$ & $51.5(47.1-55.8)^{\dagger}$ & $9000-9750$ & Transportation and Material Moving & $30.4(28.8-32.0)^{\dagger}$ \\
\hline 4000 & Chefs and head cooks & $47.8(38.3-57.2)^{\dagger}$ & $4000-4160$ & Food Preparation and Serving Related & $21.1(19.2-22.9)$ \\
\hline 0220 & Construction managers & $45.7(38.4-53.1)^{\dagger}$ & $0010-0430$ & Management & $17.5(16.4-18.6)$ \\
\hline 6355 & Electricians & $44.0(37.7-50.2)^{\dagger}$ & $6200-6940$ & Construction and Extraction & $49.4(47.2-51.6)^{\dagger}$ \\
\hline 6200 & $\begin{array}{l}\text { First-line supervisors of construction trades } \\
\text { and extraction workers }\end{array}$ & $44.0(37.4-50.5)^{\dagger}$ & $6200-6940$ & Construction and Extraction & $49.4(47.2-51.6)^{\dagger}$ \\
\hline 0205 & $\begin{array}{l}\text { Farmers, ranchers, and other agricultural } \\
\text { managers }\end{array}$ & $43.2(34.9-51.5)^{\dagger}$ & 0010-0430 & Management & $17.5(16.4-18.6)$ \\
\hline 6420 & Painters and paperhangers & $36.6(29.4-43.9)^{\dagger}$ & $6200-6940$ & Construction and Extraction & $49.4(47.2-51.6)^{\dagger}$ \\
\hline 6440 & $\begin{array}{l}\text { Pipelayers, plumbers, pipefitters, and } \\
\text { steamfitters }\end{array}$ & $35.4(28.7-42.1)^{\dagger}$ & $6200-6940$ & Construction and Extraction & $49.4(47.2-51.6)^{\dagger}$ \\
\hline 4760 & Retail salespersons & $31.3(27.7-35.0)^{\dagger}$ & $4700-4965$ & Sales and Related & $20.7(19.3-22.1)$ \\
\hline 9130 & Driver/sales workers and truck drivers & $30.4(27.8-33.0)^{\dagger}$ & $9000-9750$ & Transportation and Material Moving & $30.4(28.8-32.0)^{\dagger}$ \\
\hline Total & All occupations & $27.4(26.9-27.9)$ & & & \\
\hline \multicolumn{6}{|l|}{ Female } \\
\hline 2600 & Artists and related workers & $45.5(25.7-75.5)^{\dagger}$ & $2600-2960$ & Arts, Design, Entertainment, Sports, and Media & $8.8(6.7-11.5)$ \\
\hline 9620 & $\begin{array}{l}\text { Laborers and freight, stock, and material } \\
\text { movers, hand }\end{array}$ & $20.9(14.9-28.8)^{\dagger}$ & $9000-9750$ & Transportation and Material Moving & $12.5(10.2-14.7)^{\dagger}$ \\
\hline 4610 & Personal care aides & $12.1(9.0-16.0)^{\dagger}$ & $4300-4650$ & Personal Care and Service & $8.4(7.2-9.5)$ \\
\hline 4760 & Retail salespersons & $11.5(9.3-13.7)^{\dagger}$ & $4700-4965$ & Sales and Related & $7.1(6.3-7.8)$ \\
\hline 4110 & Waiters and waitresses & $11.3(9.1-13.4)^{\dagger}$ & $4000-4160$ & Food Preparation and Serving Related & $7.8(6.7-8.8)$ \\
\hline 3600 & Nursing, psychiatric, and home health aides & $10.2(8.3-12.0)^{\dagger}$ & $3600-3655$ & Healthcare Support & $10.6(9.2-12.1)^{\dagger}$ \\
\hline 3255 & Registered nurses & $10.1(8.6-11.6)^{\dagger}$ & $3000-3540$ & Healthcare Practitioners and Technical & $8.5(7.6-9.4)$ \\
\hline Total & All occupations & & & $7.7(7.5-8.0)$ & \\
\hline
\end{tabular}

Abbreviation: $\mathrm{Cl}=$ confidence interval.

* Per 100,000 civilian, noninstitutionalized working persons aged 16-64 years.

† Statistically higher than population rate (all occupations) based on $95 \% \mathrm{Cl}$ of occupational group rate not containing the total population rate point estimate.

$\S$ Alaska, Arizona, Colorado, Connecticut, Georgia, Hawaii, Illinois, Indiana, lowa, Kansas, Kentucky, Maine, Maryland, Massachusetts, Michigan, Minnesota, New Hampshire, New Jersey, New Mexico, New York, North Carolina, Ohio, Oklahoma, Oregon, Pennsylvania, Rhode Island, South Carolina, Utah, Vermont, Virginia, Washington, and Wisconsin.

" Number of suicide decedents $=15,779$.

** Census Bureau 2012 industry and 2010 occupational codes from the 2016 American Community Survey, translated from National Institute for Occupational Safety and Health Industry and Occupation Computerized Coding System codes using Census Bureau definitions (https://www.census.gov/topics/employment/industryoccupation/guidance/code-lists.html).

needs of coworkers, friends, family, and others who might themselves be at risk $(1,10)$. Other community-based strategies include strengthening economic supports, strengthening access and delivery of care, teaching coping and problem-solving skills, and responsibly reporting suicide (e.g., not providing details) (1). Further workplace prevention resources are available at https://workplacesuicideprevention.com/ and 


\section{Summary}

What is already known about this topic?

Suicide among the U.S. working-age population (ages 16-64 years) is increasing; in 2017 , nearly 38,000 persons died by suicide.

What is added by this report?

National Violent Death Reporting System data from 32 states were used to calculate suicide rates for major industry and occupational groups and detailed occupational groups. Five industry groups and six major occupational groups had higher suicide rates than did the overall study population. Suicide rates for detailed occupational groups provide insight into subcategories within major groups.

What are the implications for public health practice?

Opportunities exist for targeted and broadscale prevention. CDC's Preventing Suicide: A Technical Package of Policy, Programs, and Practices provides strategies to prevent suicide and can serve as a resource for communities and employers.

https://theactionalliance.org/communities/workplace and help is available at 1-800-273-TALK (8255).

\section{Acknowledgments}

Susan Burton, Matt Hirst, Jeff Purdin, Marie Haring Sweeney, Division of Field Studies and Engineering, National Institute for Occupational Safety and Health, CDC; the 32 states that added industry and occupation data to the 2016 National Violent Death Reporting System.

Corresponding author: Cora Peterson, vsm2@cdc.gov, 770-488-0699.

${ }^{1}$ Division of Injury Prevention, National Center for Injury Prevention and Control, CDC; ${ }^{2}$ Spokane Mining Research Division, National Institute for Occupational Safety and Health, CDC; ${ }^{3}$ Division of Field Studies and Engineering, National Institute for Occupational Safety and Health, CDC.

All authors have completed and submitted the International Committee of Medical Journal Editors form for disclosure of potential conflicts of interest. No potential conflicts of interest were disclosed.

\section{References}

1. Stone DM, Holland K, Bartholow B, Crosby A, Davis S, Wilkins N. Preventing suicide: a technical package of policies, programs, and practices. Atlanta, GA: US Department of Health and Human Services, CDC, National Center for Injury Prevention and Control; 2017. https:// www.cdc.gov/violenceprevention/pdf/suicideTechnicalPackage.pdf

2. US Bureau of Labor Statistics. Labor force statistics from the current population survey: concepts and definitions. Washington, DC: US Department of Labor, US Bureau of Labor Statistics; 2018. https://www. bls.gov/cps/definitions.htm\#occupation

3. National Center for Health Statistics. Vital statistics of the United States: mortality, 1999 technical appendix. Hyattsville, MD: US Department of Health and Human Services, CDC, National Center for Health Statistics; 2004. https://www.cdc.gov/nchs/data/statab/techap99.pdf

4. Peterson C, Stone DM, Marsh SM, et al. Suicide rates by major occupational group - 17 states, 2012 and 2015. MMWR Morb Mortal Wkly Rep 2018;67:1253-60. https://doi.org/10.15585/mmwr.mm6745a1

5. Milner A, Spittal MJ, Pirkis J, LaMontagne AD. Suicide by occupation: systematic review and meta-analysis. Br J Psychiatry 2013;203:409-16. https://doi.org/10.1192/bjp.bp.113.128405

6. Phillips JA, Hempstead K. Differences in U.S. suicide rates by educational attainment, 2000-2014. Am J Prev Med 2017;53:e123-30. https://doi.org/10.1016/j.amepre.2017.04.010

7. Daly MC, Wilson DJ, Johnson NJ. Relative status and well-being: evidence from U.S. suicide deaths. Rev Econ Stat 2013;95:1480-500. https://doi.org/10.1162/REST_a_00355

8. Milner A, Witt K, Maheen H, LaMontagne AD. Access to means of suicide, occupation and the risk of suicide: a national study over 12 years of coronial data. BMC Psychiatry 2017;17:125. https://doi.org/10.1186/ s12888-017-1288-0

9. Milner A, Witt K, LaMontagne AD, Niedhammer I. Psychosocial job stressors and suicidality: a meta-analysis and systematic review. Occup Environ Med 2018;75:245-53. https://doi.org/10.1136/ oemed-2017-104531

10. Milner A, Page K, Spencer-Thomas S, Lamotagne AD. Workplace suicide prevention: a systematic review of published and unpublished activities. Health Promot Int 2015;30:29-37. https://doi.org/10.1093/heapro/dau085 